\title{
EN EL GERMEN DEL LIBERALISMO ESPAÑOL: LA FILOSOFÍA NEOESTOICA EN LOS DESASTRES DE LA GUERRA DE GOYA
}

\author{
José Manuel B. López Vázquez \\ Universidade de Santiago de Compostela
}

\begin{abstract}
RESUMEN
El mismo neoestoicismo que a principios del siglo XVII sirvió -como dice Domínguez Manzano- para "la construcción de un sistema moral autónomo, justificable por sí mismo e independiente de imposiciones doctrinarias externas, pero que no dejase de ser compatible con los principales dogmas del cristianismo", volvió a ser útil a Goya como propuesta filosófica personal y colectiva, cuando nuevamente Europa y, particularmente España, ardía nuevamente en guerra. Era entonces el momento de afirmar una vez más el derecho natural, el individualismo y la razón, -elementos consustanciales a la condición humana-, frente a la ignorante barbarie o los dogmas absolutistas imperantes. Al proponer esta solución estoica, Goya no está volviendo anacrónicamente a una moral del pasado, sino a una que tenía plena actualidad y que se convertirá en una fuente esencial para el desarrollo de la ideología liberal, que adquirirá su apogeo, a partir de las fatales consecuencias de las guerras napoleónicas. En el artículo se analizan desde la estampa 26 No se puede mirar hasta la 39 Grande Hazaña con muertos.
\end{abstract}

Palabras clave: Goya, Desastres de la guerra, Neoestoicismo

\section{ABSTRACT}

The selfsame neostoicism that at the beginning of the seventeenth century helped -as Domínguez Manzano states- "to build an autonomous moral system, justifiable in itself and independent from external doctrinary impositions, but at the same time compatible with the main Christian dogmas", became the basis of Goya's personal and collective philosophical proposal at a time when Europe, and Spain in particular, had once again been plunged into war. In response, there arose a need to assert natural law, individualism and reason -elements integral to the human condition- in the face of rampant barbarism and the prevailing absolutist dogma. In offering this stoic solution, Goya is not turning anachronistically to a past moral but to an emphatically modern one that would become an essential source for the development of liberal ideology, which would reach its peak with the disastrous consequences of the Napoleonic wars. This paper analyses The Disasters of War from print 26 No se puede Mirar (One cannot look) through to 39 Grande Hazaña con muertos (A heroic feat! With dead men!).

Keywords: Goya, The Disasters of War, neostoicism

Ya en mi ponencia "Los Desastres de la guerra como un libro de emblemas estoicos" expuesta en el "I Simposio Internacional Jóvenes Investigadores del Barroco Iberoamericano: identidades culturales de un imperio barroco", que se celebró en mayo de $2013^{1}$, desarrollé, las distintas interpretaciones que la historiografía había hecho de esta serie, los cambios y mutilaciones que ella había sufrido y la necesidad de llevar a cabo una nueva interpretación a las realizadas hasta la fecha, partiendo de la premisa de que Goya, como pintor de la llustración, tiene como principal finalidad enseñar a amar la virtud y odiar al vicio, convirtiéndose así en un pintor "filósofo", lo que en este contexto significa: ser un divulgador de enseñanzas morales siguiendo la máxima horaciana de instruir deleitando ${ }^{2}$. Para conseguirlo, él no tiene por qué inventar una nueva filosofía, sino simplemente dar forma plástica a una vigente o que podría recobrar vigencia en su momento histórico. 
En este sentido, en dicha ponencia destacaba la influencia que a lo largo de la vida de Goya, ejerció sobre su pensamiento el proemio y las glosas de la Emblemata Horaciana de Vaenius, tanto de la edición francesa, como de la española ${ }^{3}$, redactadas las primeras por de Marino Le Roy $^{4}$ y atribuidas las segundas a Antonio Brum ${ }^{5}$, aunque ambas inspiradas en postulados neoestoicos. Esta corriente filosófica de pensamiento, fue fundamental no solo en la configuración del ser barroco español -particularmente, en autores también decisivos para el pensamiento de Goya como Quevedo y Gracián, que le añadieron además originalidad a través de su concepción del "desengaño"6-, sino que permaneció disponible durante toda la ilustración española. Al fin y al cabo, alguno de los puntos básicos de esta doctrina, como son la defensa de una moral interior, el desprecio del cuerpo, la denuncia de los excesos de la jerarquía eclesiástica y de las prácticas supersticiosas, etc. coinciden con las ideas jansenistas, entonces en plena ebullición en España, y, posiblemente, Goya, como muchos ilustrados españoles, al hilo de la polémica jansenista, había recuperado trazas de la vía erasmista y estoica omnipresente en los escritores áureos. Pero es más, el mismo neoestoicismo que a principios del siglo XVII sirvió -como dice Domínguez Manzano- para "la construcción de un sistema moral autónomo, justificable por sí mismo e independiente de imposiciones doctrinarias externas, pero que no dejase de ser compatible con los principales dogmas del cristianismo"7, volvió a ser útil a Goya como propuesta filosófica personal y colectiva, cuando nuevamente en Europa y, particularmente en España -como él mismo ilustra en su Desastre 42 Todo va revuelto-, ardía en guerra. Era entonces el momento de afirmar una vez más el derecho natural, el individualismo y la razón, -elementos consustanciales a la condición humana-, frente a la ignorante barbarie o los dogmas absolutistas que imperaban por doquier. Al proponer esta solución estoica, Goya no está volviendo anacrónicamente a una moral del pasado, sino a una que tenía plena actualidad y que se convertirá en una fuente esencial para el desarrollo de la ideología liberal, que adquirirá su apogeo, precisamente, a partir de las fatales consecuencias de las guerras napoleónicas.
También en la citada ponencia señalaba que, en época de Goya, la elaboración del discurso para un programa iconográfico, era similar al seguido en los sermones, en los que se engarzaban distintas ideas extraídas de diferentes libros ${ }^{8}$. Sin embargo, es frecuente, tanto en el arte peninsular como en el iberoamericano, el hecho de que los artistas desarrollaran sus programas limitándose a copiar los grabados de un único libro o a saltear en un nuevo discurso grabados tomados de varios, cuyas figuras reproducían literalmente. Ciertamente, quienes así actuaban eran meros artesanos, pues carecían de la invención $y$, consecuentemente, de la originalidad, que es lo que caracteriza al verdadero artista. Por otra parte, debemos tener en cuenta que, en la literatura emblemática, la elaboración de un nuevo emblema se basaba, generalmente, en hacer un refrito de los comentarios de otras precedentes, cambiando los lemas, las figuras, o ambas cosas al tiempo. A los autores que así obraban nadie les negaba el calificativo de inventor.

Yo creo que Goya siguió, con diversas variaciones, este último modo. Unas veces se limitó a tomar los contenidos de los emblemas del Theatro Moral, inventándoles nuevas figuras (por ejemplo os cartones para el Dormitorio y ante dormitorio de los Príncipes de Asturias); otras, lo que tomaba era el argumento de una obra como la Tabla de Cebes con el cual realizó el programa de los cartones para el Comedor de los Príncipes de Asturias del Palacio del Pardo en 1776, y, con mayor frecuencia se dedicaba a ir ilustrando un texto tomado de un autor. Por ejemplo, la mayoría de los Caprichos siguen los comentarios a tres de las Empresas Políticas de Saavedra Fajardo. En el caso de Los Desastres, su primera parte, que abarca desde la estampa primera hasta la trigésimo nona, Goya sigue una línea argumental extraída del Proemio del Theatro Mora ${ }^{9}$ con la que elabora un conjunto de exvotos para el desengaño, ilustrando los medios de cómo adelantar en el estudio de la verdadera sabiduría, la cual se basa en el temor de Dios -al que remite la estampa introductoria: Tristes presentimientos de lo que ha de acontecer-. Dichos medios son cuatro:

El primero: apartar de si todos los falsos principios, y opiniones adquiridos por la mala institu- 
ción, por vanas lecturas, o por mal exemplo. Lo segundo: huir de las ruines compañías y procurar imitar a los más virtuosos y sabios. Lo tercero: ser tan bueno en lo interior, como se desea parezer en lo exterior. Y lo quarto y último es: emplear el entendimiento, en conozer y elegir lo que verdaderamente es bueno y loable; y aplicar la voluntad a quererlo y amarlo ${ }^{10}$.

Precisamente a ilustrar el primero de los medios Goya dedica las estampas desde Con razón o sin ella hasta Se aprovechan, como ya analicé en la ponencia citada. Posteriormente, en una comunicación presentada en el IX Congreso Internacional de la Sociedad Española de Emblemática "Confluencia de la imagen y la palabra. Emblemática y artificio retórico", analicé como Goya ilustró el segundo de dichos medios desde la estampa No se convienen hasta También estos. En este artículo trataré de mostrar como Goya ilustró el tercer y cuarto medio.

\section{Tercer medio de conseguir la virtud}

Según Antonio Brum, el tercer medio para conseguir la virtud estriba en "ser tan bueno en lo interior, como se desea parezer en lo exterior". A plasmarlo Goya dedica las estampas 26 y 27 de Los Desastres: No se puede mirar (Fig. 1) y Caridad (Fig. 2). Tras ellas pudiéramos percibir el eco de la discusión que encontramos en la literatura emblemática de qué hacer con los prisioneros. El comportamiento virtuoso sería el de ejercer la clemencia ${ }^{11}$ y la compasión con los enemigos ${ }^{12}$, precisamente, el contrario que manifiestan los vencedores en las estampas. Así, en la primera, los prisioneros están a punto de ser fusilados por un batallón inclemente e inhu-

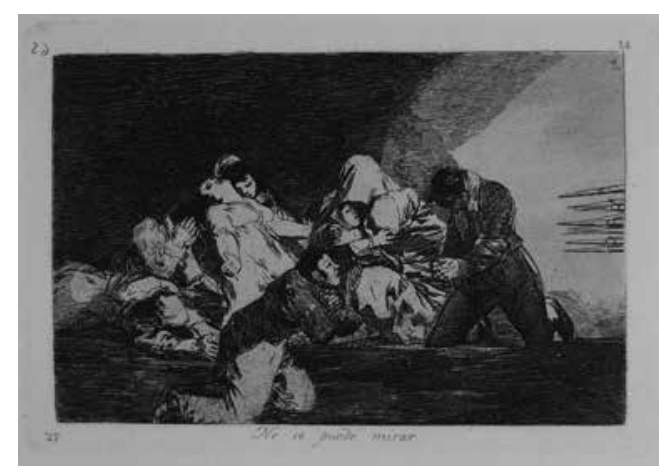

Fig. 1. Goya. No se puede mirar mano. Pero con la clave estoica la interpretación esta estampa se enriquece con nuevos matices. Debemos tener en cuenta que Goya en los epígrafes de Los Desastres, como ya había hecho en los de los Caprichos, no solo juega con la ambigüedad, sino que imita -tanto en el estilo, como en el contenido- el lenguaje popular que utiliza locuciones ingeniosas y frases hechas con las que, sentenciosamente, se manifiestan juicios cargados de doctrina, aunque, al ser estas dichas rutinariamente, sin que quien las dice reflexione sobre la moralidad que ellas verdaderamente implican, no siempre se adecúan con propiedad al caso, lo cual es frecuente cuando se habla desde la ignorancia y la pasión y no desde el conocimiento y la razón. Esta forma de hablar no es exclusiva del pueblo ignorante, sino que es compartida por los ingenios más agudos, los cuales -a decir de Brum en su Proemio-, precisamente por su mucha inteligencia, son incapaces de alcanzar la verdadera sabiduría ${ }^{13}$. De hecho, el redactor de los epígrafes de Los Desastres Goya, es un español de ingenio agudo y perteneciente al bando 'patriota', que, por ambas causas -pues, la primera le llevará a no reflexionar sobre lo que percibe por los sentidos y la segunda a ver la realidad apasionadamente distorsionada por su sectarismo 'patriótico'-, caerá constantemente en errores de apreciación, hasta que finalmente empiece a atisbar la sabiduría y dé en el desengaño, lo que no acontece, como veremos, hasta la estampa Esto es peor.

Por ello, si entendiésemos No se puede mirar desde el punto de vista del autor de la letra -recuerdo de ingenio agudo, pero poco reflexivo-, muy posiblemente deberíamos quedarnos con

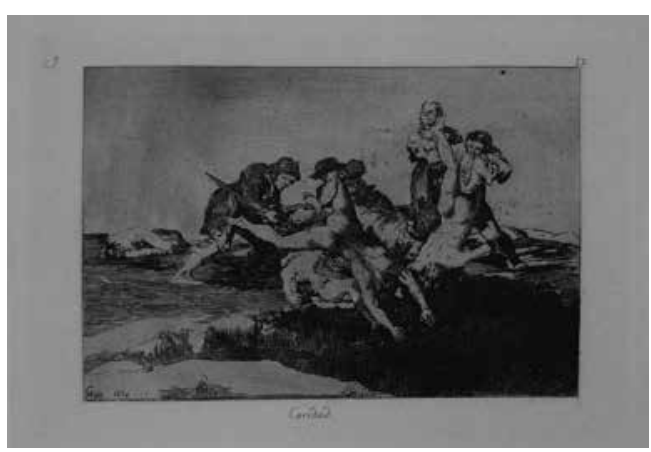

Fig. 2. Goya. Caridad 
la idea de que no podemos mirar porque hiere nuestra sensibilidad la inhumana actuación del ejército francés y la propia dureza de la escena. Como tampoco pueden mirar la mayoría de sus protagonistas ante la inminencia de su ejecución. Pero, además, si tenemos en cuenta que las armas van "sin dueño que las rija" -como en los fusiles de la estampa número 15 Y no hay remedio (Fig. 3)-, también podríamos colegir que

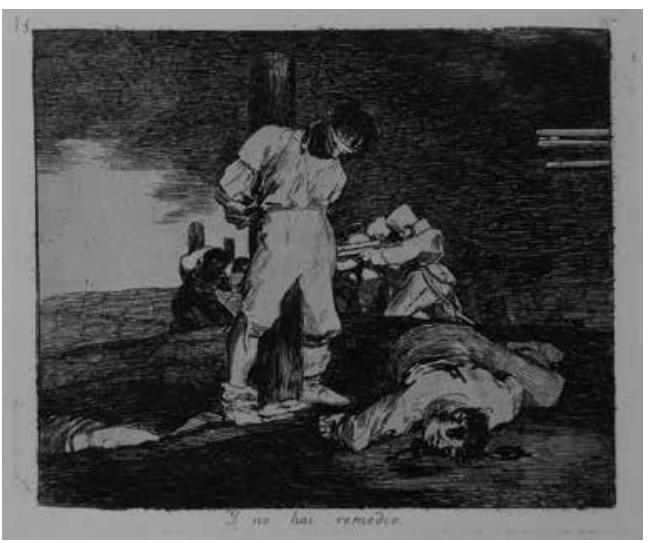

Fig. 3. Goya. Y no hay remedio

tampoco los soldados franceses pueden mirar, porque, como ocurría en aquella, ellos no ven a causa de su ira ${ }^{14}$.

Sin embargo, teniendo en cuenta la clave neoestoica, también creo que el acento de la moraleja del grabado está puesto, principalmente, en las víctimas, porque, en definitiva, es el modo de comportarse de estas el que ha desencadenado los hechos a cuyo desenlace estamos a punto de asistir. $Y$ es que ellas no son tan buenas en lo interior, como desean parecer en los exterior a través sus gestos, que, por cierto, resultan vanos cuando ya no hay tiempo para tornar los acontecimientos. Ellas, ahora, se presentan implorantes y humildes, lo que las lleva a arrodillarse e incluso arrastrarse por los suelos, a juntar las manos uniendo o cruzando los dedos en señal de suplica u oración, taparse con ellas el rostro mostrando desesperación, a abrir los brazos en cruz, aparentemente, en señal de misericordia ${ }^{15}$, o sentarse protegiendo a los niños exhibiendo mucha clemencia ${ }^{16}$. Realmente, si en su interior fuesen así, humildes, misericordiosas y clementes, sin duda no habrían llegado a la situación en que se encuentran, pero la verdad es que ellas son viciosas y como tales actúan. Así, la figura arrodillada del primer término es corcovada, lo que nos lleva a recelar que también torcida y llena de dobleces en la intención ${ }^{17}$ y ponernos en guardia a pesar de que sus facciones con la nariz redonda ${ }^{18}$, la quijada grande y carnosa $^{19}$, los ojos bovinos, y la boca abierta nos pueden llevarnos a engaño pensando que se trata tan solo de un mentecato; el que está arrodillado en el extremo derecho de la composición tiene la nariz aguileña, por lo que pudiéramos pensar que es un hombre generoso ${ }^{20}$ e incluso "excelente por naturaleza"21, pero si también tenemos en cuenta su ojo de ave de rapiña y apreciamos sus facciones de cernícalo, podemos deducir que es un hipócrita codicioso que solo piensa en la propia conveniencia, para lo cual no dudaría en robar ${ }^{22}$. Evidentemente él es un hombre sin vergüenza ${ }^{23}$. Tampoco es de fiar a mujer sentada que aparenta clemencia, acogiendo contra su seno a un niño y a un bulto, pues aquel es un monstruo -a juzgar por su deformidad y la extraña protuberancia que le sobresale en la mejilla- y este pudiera ser otro niño todavía más deforme. Niños a los que ella utiliza, so capa de clemente, para ganarse pícaramente la vida, valiéndose de la compasión de la gente ${ }^{24}$. La muchacha que aparenta misericordia, abriendo los brazos, muy posiblemente actúe en su vida cotidiana acogiendo a hombres, pero no tanto por caridad, como para satisfacer y sacar provecho de su propia voluptuosidad -véase como indicios de esto, su ancha nariz ${ }^{25}$, ojos extasiados y la forma de echar hacia atrás orgásmicamente la cabeza- mientras que la somnolencia de su compañera, sin duda debida a su complexión flemática y a su natural ociosidad, refuerza la idea de prostitución. La vieja que se arrastra detrás de ellas, más que humilde, probablemente sea una sabandija rastrera, dada a tercerías. Y el hombre que a su lado se cubre el rostro con ambas manos, posiblemente posea una complexión sanguínea -a juzgar que es dado a derramar lágrimas cuando ya no son necesarias-, que le hace vivir esclavo de la sensualidad a la que le llevan sus imperiosos y cambiantes deseos ${ }^{26}$.

Así analizada la escena, nos damos cuenta hasta que punto yerra el autor de la letra cuando nos dice que "no se puede mirar". Por el contra- 


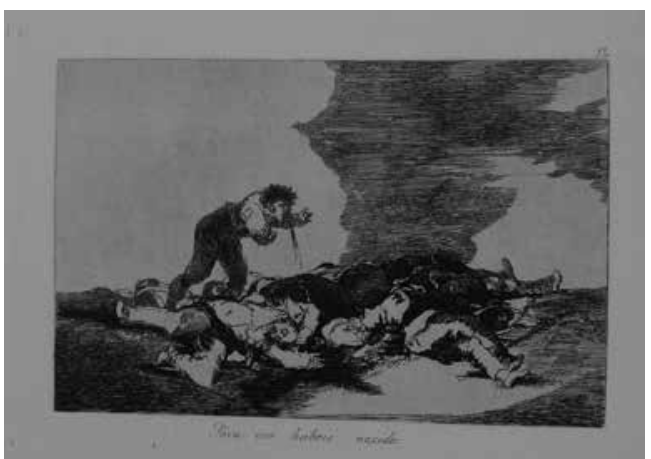

Fig. 4. Goya. Para eso habéis nacido

rio, Goya, nos impele a mirar y remirar utilizando el recurso barroco de llamada -centrándonos en dónde apuntan las bayonetas- para de este modo demos en el desengaño y no acabar siendo solo despojos humanos, como muy pronto lo acabarán siendo estos protagonistas o como ya lo son los de la estampa 12 Para eso habéis nacido (Fig. 4).

Si en la estampa No se puede mirar posiblemente eran soldados franceses los que se aprestaban a fusilar a españoles, en la siguiente, Caridad, es muy posible que sean estos los que arrojan a una fosa común los cadáveres de aquellos. Sin embargo, también aquí la finalidad de la estampa sigue siendo la misma: mostrar que sus protagonistas no son tan buenos en lo interior como desean parecer en lo exterior. Aparentemente, ellos están practicando la última de las obras de misericordia corporales: enterrar a los muertos. Cuando hayan terminado de hacerlo, habiendo echado la tierra encima de los cuerpos, podrán aparecer ante los demás, empezando por el ejército enemigo, como personas misericordiosas y, por consiguiente, tan buenas como quieren parecer. Sin embargo, como Goya los representa precisamente en el momento en que están deshaciéndose de los cadáveres, tratándolos como si fueran los de alimañas, muestra que ellos son, en realidad, unos viciosos que violan la citada obra de misericordia, según la cual:

El cuerpo ya muerto del Christiano es tratado con respeto, por ser un órgano del alma que se presume estar gozando de Dios, o en camino de gozarle. Visténle conforme al oficio que tuvo en vida [...] a los demás ponen mortaja de lienzo blanco, para denotar la pureza con la que el alma del Christiano debe parecer delante del Tribunal de Dios, correspondiendo a la que tuvo quando se bautizó y le pusieron capilla de lienzo blanco, el qual tiene correspondencia con la mortaja. Es luego llevado a sepultar acompañándole la cruz, clerecería [...] cantando todos la Letanía, Psalmos de David, conforme a la costumbre de la tierra ${ }^{27}$.

Pues, aunque es cierto que estamos en tiempos de guerra, ello no debería impedir guardar el respeto debido al cadáver, depositándolo con humanidad en la cárcava y, además de no desnudarlo por completo -aunque lo ideal sería conservarle el uniforme militar-, portar una cruz y dar lectura a un mínimo oficio religioso, mientras se lleva a cabo su sepultura. Por eso, nuevamente yerra el autor de la letra, cuando sin reflexionar sobre lo que sus sentidos perciben, cree que lo que están haciendo los protagonistas de la estampa es "caridad", cuando lo que hacen es, simplemente, hipocresía y buscar su propio provecho tratando de evitar la ira desbocada del enemigo o, incluso, el mero desencadenamiento de pestes y enfermedades. Únicamente el personaje que está de pie, y que no participa en la acción, parece mantener el decoro apropiado al momento.

\section{Cuarto y último medio de conseguir la virtud.}

Según Antonio Brum, el último medio de conseguir la virtud es: "emplear el entendimiento en conozer y elegir lo que verdaderamente es bueno y loable; y aplicar la voluntad a quererlo, y amarlo". En el propio Proemio, él desarrolla más su pensamiento diciendo:

$Y$ assi qualquiera tuviera firme y constante voluntad usar la razón, mejor que lo fuere possible, $y$ de hazer en todas sus acciones lo que juzgare ser bueno; es verdaderamente tan sabio como su talento lo permite; y a la misma proporción, será fuerte, justo, y templado y tendrá todas las demás Virtudes; pero tan unidas entre sí, que ninguna vendrá a sobrepujar la otra. Por lo qual, aunque estas sean mucho más perfectas, que las que el error o ignorancia del vulgo celebra más pomposas, y ostentativas; todavía, como las conoce menos, no acostumbre alabarlas tanto como essotras.

Demás de esto, de dos cosas que se requieren para alcanzar la Sabiduría assí definida (que son, que el entendimiento conozca lo que es bueno, y 
que la voluntad esté pronta a seguirlo, y amarlo) en la segunda sola (que consiste en la voluntad) pueden ser iguales todos los hombres; pero no en la primera, por no ser todos los entendimientos iguales. $Y$ aunque los que le tiene mediano, pueden ser tan perfectamente sabios como su natural talento lo permite, y hazerse muy agradables a Dios por su virtud, teniendo siempre una firme resolución de hazer todo el bien que conozen; y no olvidar medio alguno de aprender de sus Directores lo que ignoran; no obstante, los que (con una constante voluntad de obrar bien, y un particular cuydado de instruirse) tienen el entendimiento aventajado; llegan sin duda, a más alto grado de Sabiduría que los otros [...] La razón porque los más agudos y penetrantes ingenios, no son los más propios para esta professión (como apunte arriba) es, porque presumiendo de si, más de lo que son; gastan la mayor parte de su vida en la curiosidad de querer saber y examinar; lo que solamente aperciben por los sentidos, sin hazer jamás una sola reflexión sobre los mismos, que es el verdadero principio de este estudio, sin el qual todas las demás sciencias son inútiles [...] No obstante tengo por exemptos y exclusos destas dos Reglas, aquellos ingenios claros, que por un don, y luz particular del Cielo, llegan a ser maduros antes de tiempo (que son harto raros) y aquellos que tienen la dicha de tener Padres virtuosos y exemplares, desde los tiernos años, los acostumbran a la Virtud. Estos (por institución y hábito) y aquellos (por el raro, y rico don de naturaleza) llegan con harta facilidad y a la verdadera perfección.

Todos los demás que van descaminados; pecan de yerro, o por ignorancia o por duda. Yerro llamo, aquel sentimiento, o opinión que repugna a la razón, y a la verdad. En esta flaqueza caben todos aquellos que de las Escuelas sacaron malos principios, o entendieron mal la Doctrina de sus Maestros. Estos parecen los más incurables, por ser los más contumazes. La ignorancia (en la materia que voy tratando) es no aprobar, ni reprobar lo que no se sabe, o no se entiende: y se remedia con sugetarse a la instrucción y buen consejo de los Directores. También ay ignorancias loables, y de grande utilidad; como es la de aquellos que se contenta con saber lo que les basta para la pureza de su conciencia. Esta se llama ignorancia voluntaria; a diferencia de otra que ay Magistral, que perteneze a los muy doctos, a quienes el largo estudio, y desvelos, les dieron a conozer que es infinito mas lo que el hombre ignora, que quánto puede alcanzar a saber; De donde se infiere, que el más alto grado se sciencia feneze en principio desta sabia ignorancia, que confesó Socrates quando dixo. Unum scio, quod nihil scio. Pero estos dos géneros de ignorancia, no sólo impiden el Estudio de la Sabiduría, sino que son mayores sus perfecciones. La duda de que hablo aquí, no es aquella que usan los Prudentes en la variedad de sentencias y opiniones; hasta estar muy bien informados: (antes esta es muy útil, para aprovechar mucho en las sciencias) sino aquella que procede de flaqueza de entendimiento, que por incapaz de instrucción viene a parar en escrúpulos muy dañosos a la conciencia, y contrarios a la Virtud. Algunos sanan desta enfermedad por la destreza y prudencia de los Médicos espirituales, y otros mueren incurables.

En mi opinión Goya utiliza el último párrafo reproducido como línea argumental de la estampa 28, Populacho a la 39 Grande hazaña con muertos, ilustrando a los que se apartan del camino de la virtud por yerro, ignorancia o duda, para mostrarnos como el desvío del hombre del sendero de la virtud trae consigo su quebrantamiento de todas las virtudes, empezando por la de la fortaleza que debilitándose hace que la voluntad no se obligue a lo que la razón dicta, lo que da lugar a acciones injustas y destempladas. Al fin y al cabo, la justicia es la virtud que epitomiza y compendia a todas las demás y la que más evidentemente se viola so pretexto de la guerra. Recordemos lo que decía Saavedra Fajardo: "Son medrosas las leyes, y se retiran y callan cuando ven las armas. Por esto dijo Mario excusándose de haber cometido en la guerra algunas cosas contra las leyes de la patria, que no las había oído con el ruido de las armas" 28 . Pero en estado de guerra, no sólo se violan las leyes establecidas, sino que además se dictan otras nuevas, que en muchas ocasiones van contra la razón y el sentido común, como de hecho se hizo durante la contienda española ${ }^{29}$, provocando su aplicación flagrantes injusticias y horrores -que no solo errores-, que se incrementan cuando dichas leyes también se quebrantan al ser aplicadas con una jurisprudencia todavía más irracional.

Consecuentemente, tampoco ninguna de estas estampas tiene nada de heroico y mucho menos narran hazaña alguna. La letra de la última estampa citada, Grande hazaña con muertos, lo pone en evidencia por antífrasis, ya que el conjunto de todas ellas ilustran lo contrario de lo 
que manifestó el emperador Federico tras vencer en Hungría: "Grande hazaña se ha obrado, pero queda otra mayor, y es vencernos a nosotros mismos, y poner freno a la codicia, y al efecto de venganza"30. Aunque a los 'victoriosos' protagonistas de los lances de los grabados -sean franceses o españoles- les pudiera parecer que están realizando heroicidades, en realidad, no es así, y sí, por el contrario, obran perversamente, llevados por su mucha codicia y por su enorme afán de venganza. Al igual que para el autor del Proemio, en las siguientes estampas de Los Desastres esta forma de comportarse, contraria a la virtud, es fruto de los errores de las doctrinas seguidas, de la ignorancia o de la duda escrupulosa por cortedad de inteligencia, que les impiden a sus protagonistas emplear su entendimiento en conocer y elegir lo que verdaderamente es bueno y loable y aplicar la voluntad a quererlo y amarlo. Veámoslo:

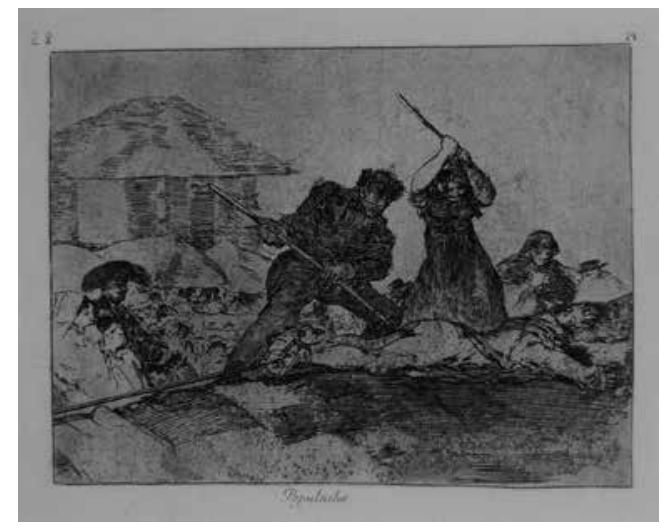

Fig. 5. Goya. Populacho

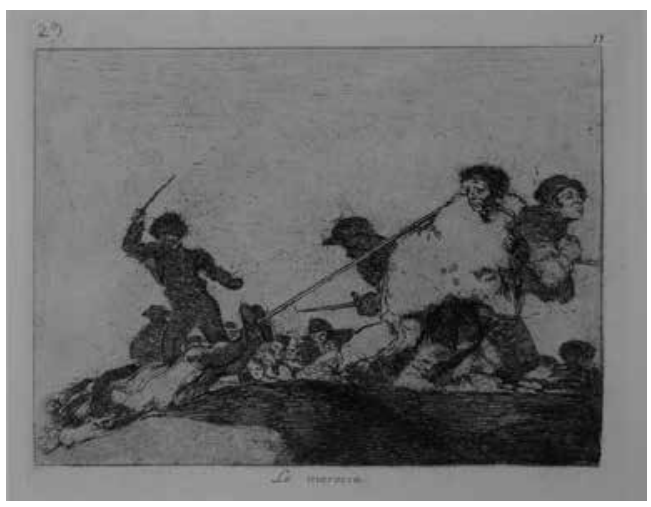

Fig. 6. Goya. Lo merecía

\section{Yerro}

La definición que Antonio Brum da yerro, no es sino una matización del primer medio que el mismo exponía para alcanzar la virtud que, recordemos, era: "apartar de si todos los falsos principios, y opiniones adquiridos por la mala institución, por vanas lecturas, o por mal exemplo". De ahí que las dos estampas -Populacho (Fig. 5) y Lo merecía (Fig. 6)- que utiliza Goya para ilustrar a los que yerran porque "de las Escuelas sacaron malos principios, o entendieron mal la Doctrina de sus Maestros", se asemejen a las que iniciaban la serie: Con razón o sin ella (Fig. 7) y Lo mismo (Fig. 8). En ambas encontramos hechos que repugnan a la razón y a la verdad y en ambas su protagonista es la plebe que, desquiciada de espanto, "se atreve a lo sangriento" 31 . Sin embargo, mientras en las primeras se incidía en la idea de que la ira y la rabia llevan al pueblo a actuar temerariamente

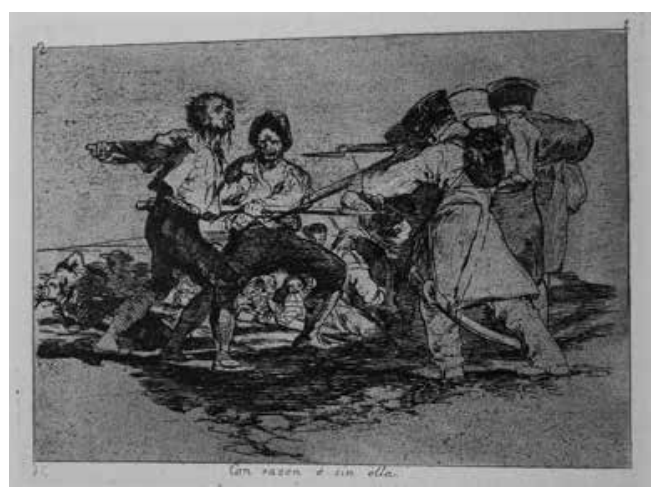

Fig. 7. Goya. Con razón o sin ella

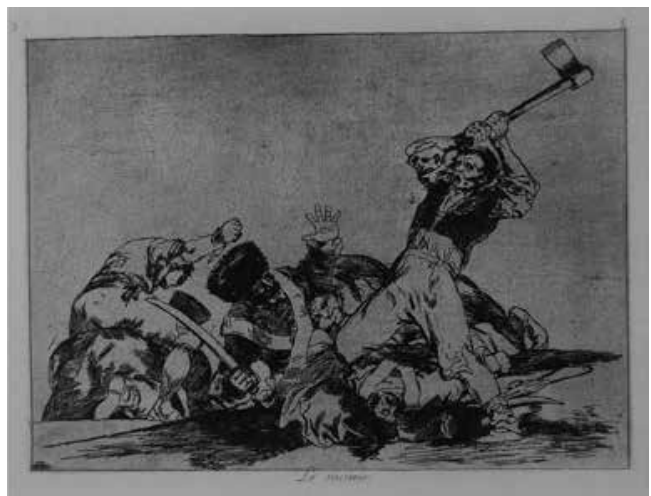

Fig. 8. Goya. Lo mismo 
revolviéndose irracionalmente contra el ejército invasor, en estas, se muestra como su enloquecimiento le lleva también a envestir contra sus propios compatriotas ${ }^{32} \mathrm{e}$, incluso, contra sus conocidos ${ }^{33}$.

El autor del epígrafe de la estampa goyesca, una vez más se engaña, al utilizar un doble rasero, pues insulta a la plebe protagonista de la primera estampa, llamándole "populacho" cuando esta "viguriza" a un compatriota arrastrándolo de los pies e infringiéndole golpes y pinchazos, porque la víctima era uno de $\operatorname{los} \operatorname{suyos}^{34} \mathrm{y}$, por el contrario, justifica un crimen semejante, diciendo que "lo merecía" cuando ella propina un castigo similar a otro hombre al que él considera su enemigo ${ }^{35}$. Sin embargo, para un conocedor de la doctrina estoica según la cual un crimen es siempre un crimen, independientemente de sus circunstancias $^{36}$, la justicia empleada aquí por la plebe, repugna por completo a la razón y, por lo tanto, es injusta, independientemente de que el reo comparta o no las ideas del espectador/lector e, incluso, del tipo de crimen que él pudiera haber cometido. Es más, si tenemos en cuenta las posturas -boca abajo y boca arriba- de lasvíctimas -y si pudiéramos intuir que ello tiene un significado más allá de ser un mero recurso compositivo en dos estampas concebidas como pendant-, podríamos colegir que el protagonista de la primera, a la que el autor de la letra defiende, -pues insulta a sus agresores- es, en realidad, mala gente; mientras que el de la segunda, al que el autor de la letra considera un malvado -ya que lo cree merecedor del castigoes, por el contrario, una buena persona ${ }^{37}$. Ello también justificaría la mirada de conmiseración del verdugo que vuelve la cabeza -ya destacada por Wolf ${ }^{38}$ - y la impasibilidad del rostro de su compañero, lo que induce a pensar que ellos están a llevando a cabo su acción obligados por alguna razón y no motu proprio. Desde luego sus fisonomías son completamente distintas a las desfiguradas por la ira que presentan el hombre y la mujer que hieren al reo en la otra estampa.

\section{Ignorancia}

A continuación Goya pasa a ilustrar la segunda causa de la pérdida del camino de la virtud que es la ignorancia, a lo que dedicará varias

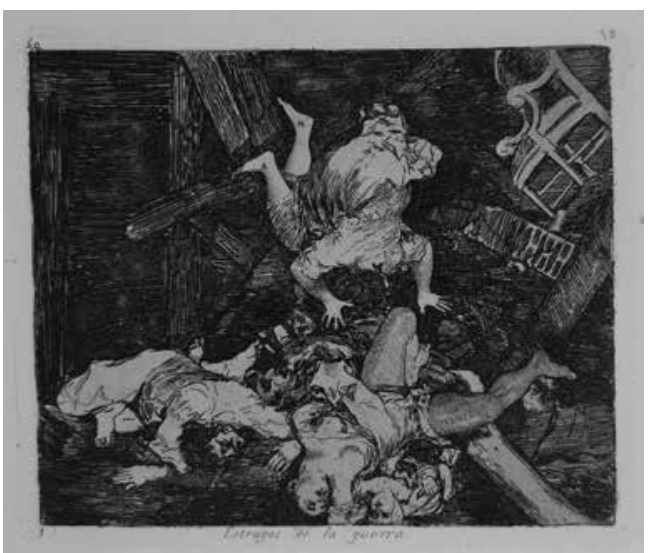

Fig. 9. Goya. Estragos de la guerra

estampas. Brum empieza diciendo que "la ignorancia (en la materia que voy tratando) es no aprobar, ni reprobar lo que no se sabe", lo que el aragonés plasma en Estragos de la guerra (Fig.9).

En esta estampa el autor de la letra no entra a valorar lo que ve, quedándose, una vez más, en lo anecdótico de lo que percibe por los sentidos sin reflexionar sobre ello, de manera que para él, lo percibido son simplemente "estragos", es decir: consecuencias colaterales de la guerra. Algo que él entiende como lógico que sucedan en toda contienda. Por lo que, aparentemente, él ni los aprueba, ni los reprueba, simplemente se limita a constatarlos. Aunque al hacerlo así, está, de hecho, aprobando, por desconocimiento, como normal, algo tan aberrante y falto de toda razón como es un bombardeo indiscrimi-

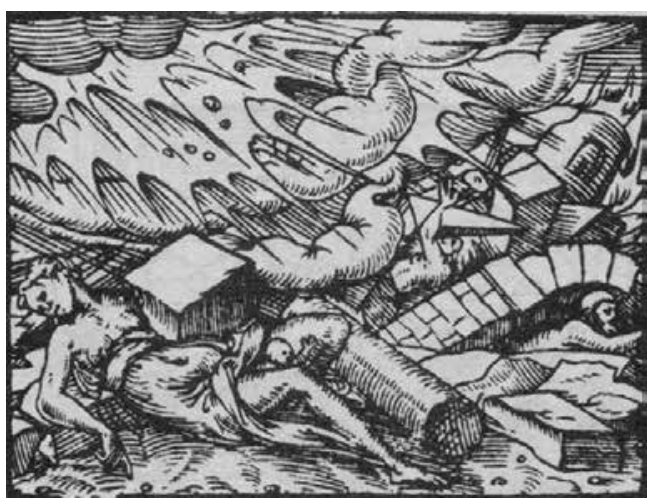

Fig. 10. Menestrier. Les villes de Sodome et Gomorrhe abysmées par le feu du Ciel pour en punir les crimes et les abominations 
nado. Por el contrario, un espectador estoico no solo nunca aprobaría dicho bombardeo, sino que, conociéndose a sí mismo y la sociedad en la que vive, reprobaría su causa última, que no es, precisamente, la propia guerra, sino porqué esta se generó: el abandono por la mayoría de las gentes que conforman dicha sociedad de la consecución de los bienes de la virtud, en pro de los materiales que otorga la fortuna.

Si tenemos en cuenta el efecto de instantánea de la escena y el erotismo de la mujer del primer término -dispuesta en posición supina-, que recuerdan a la empresa de Menestrier: Les villes de Sodome et Gomorrhe abysmées par le feu du Ciel pour en punir les crimes et les abominations (Fig. 10) ${ }^{39}$, es muy posible que nuevamente Goya estuviera utilizando icónicamente un tema de encuadre, con el que querría incidir no sólo en una referencia al castigo divino, sino también señalar su causa: la depravación de la sociedad. De hecho, una vez más, la alusión al efecto voltario y giratorio de la fortuna en la disposición de las figuras -como en la estampa 11 Tampoco (Fig.11)-, incide la idea que ellas están atrapadas en la búsqueda viciosa de los bienes mundanos que la fortuna reparte y en la que ellos fían toda su suerte; alusión a los vicios que se acrecientan en el caso de las féminas -recuérdese la misoginia de la época-, lo que se enfatiza en la mujer del primer término al mostrarnos, que ella es, realmente, una "moza de fortuna" ${ }^{40}$. Por lo tanto, no sólo está evidenciando que ella, como sus congéneres, son inconstantes e irracionales, sino también sujeto y objeto de lascivia y ya Saavedra decía que "la mayor enfermedad de la república es la incontinencia

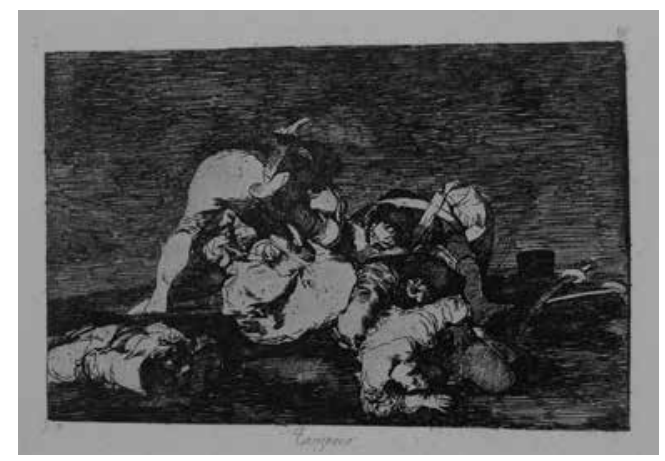

Fig.11. Goya. Tampoco

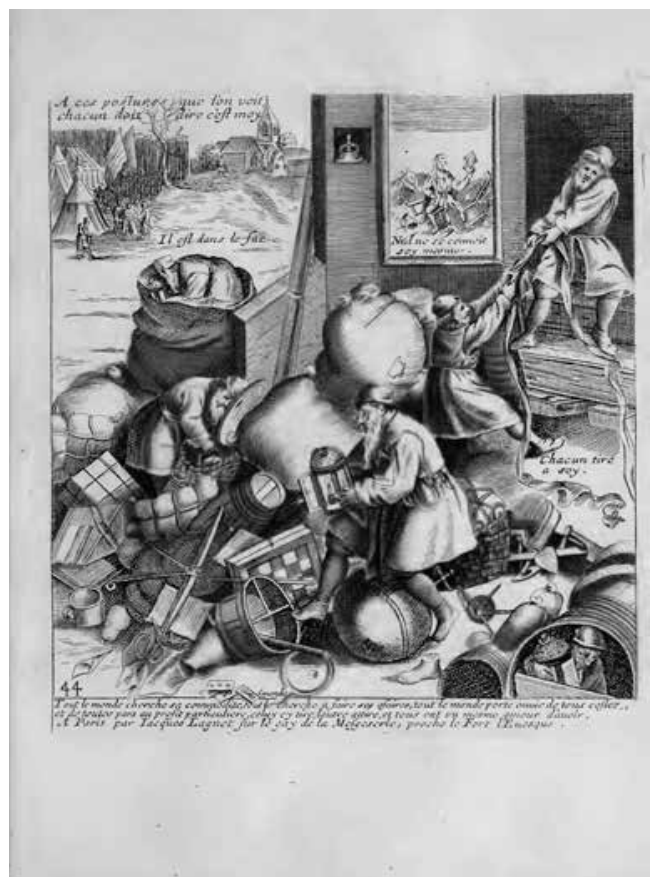

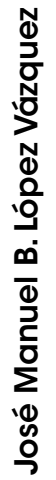

Fig.12. Jacques Lagniet Nul ne se connoit soy mesme

y lascivia". La lascivia, de hecho, era considerada el origen de todos los males, ya, que, desde la Edad Media, el pecado original descrito en el Génesis como un pecado de orgullo y un desafío del hombre hacia Dios, se había convertido en un pecado sexual ${ }^{41}$. La enseñanza que, a modo de exvoto, Goya pone ante nuestros ojos es que una sociedad necia y depravada, que vive orgullosa en la ignorancia y en el vicio, sin utilizar la razón y fiándolo todo a la fortuna -esto es: sin temor de Dios y sin conocerse ${ }^{42}-$, fatalmente no tiene otro final que terminar siendo un despojo de ella misma y un estrago de lo que ella misma genera: la guerra. Consecuentemente, tras el grabado, subyace la idea neoestoica del mundo como caos, en el que el hombre no se conoce y, por consiguiente, no conoce lo que le conviene, por lo que solo da valor a los engañosos bienes aparentes -como el lujoso sillón- mientras desecha los verdaderos y espirituales ${ }^{43}$.

Siguiendo con el texto de Brum, Goya, tras ilustrar que la "ignorancia es no aprobar, ni reprobar lo que no se sabe", muestra en la estampa siguiente ¡Fuerte cosa es! (Fig. 13) aquella ignorancia que consiste en "no aprobar, ni re- 


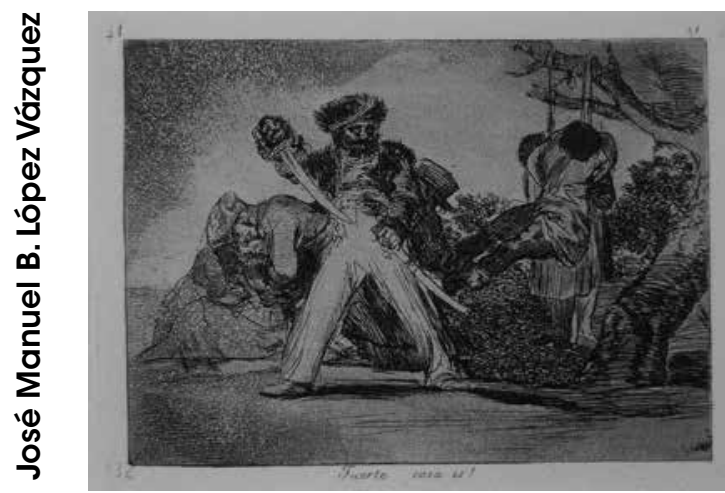

Fig.13. Goya. ¡Fuerte cosa es!

probar lo que [...] no se entiende". El autor de la letra se admira, dejando ya con ello evidente su ignorancia ${ }^{44}$, pero en este caso también hace palpable su necedad, en tanto en cuanto se limita a admirarse de algo que obviamente, a primera vista, no entiende $y$, lo que es peor, tampoco trata de entenderlo, para así poder manifestar, posteriormente, un juicio de valor, aprobándolo o reprobándolo como requiere una forma de actuar que esté guiada por la sabiduría.

De hecho, lo representado en la estampa es de difícil comprensión, cómo lo demuestran las muy distintas interpretaciones que ha tenido. Basándonos en ellas y en nuestra propia cosecha, pudiéramos preguntarnos ¿de qué se admira el autor de la letra? ¿Qué es lo que para él es fuerte cosa?: ¿toda la escena? ¿Los ahorcados? ¿La acción de tirar de las piernas de uno de ellos, que piadosamente realiza un soldado francés, para terminar antes la tarea? ${ }^{45}$ ¿O su misericordia con el cadáver para amortiguar la caída de este cuando su compañero corte la soga con su espada? ${ }^{46}$ ¿Qué, en el lado izquierdo del segundo término, un soldado este sujetando a una mujer para que otro pueda violarla? ${ }^{47}$ ¿O el dolor que está sintiendo dicha mujer, que no está siendo violada, sino que, por el contrario, está siendo consolada por él? ${ }^{48}$, ¿El grotesco soldado del primer término, que más que persona es cosa? Sinceramente no podemos decirlo, porque la escena se compone de una serie de anécdotas que son prácticamente ininteligibles; aunque, bien pensado, tampoco importa, porque en realidad es irrelevante de qué pueda admirarse un necio ignorante.
Lo verdaderamente importante es que, primero, Goya, para mostrar la ignorancia producida por la falta de entendimiento, juegue expresiva y modalmente con el estilo y haga conscientemente una composición que no solo es confusa -incluso formal y técnicamente deplorable ${ }^{49}$-, sino además caricaturesca hasta lo grotesco. Precisamente, todo ello, al no ser percibido como recursos estilísticos expresivos del propio contenido de la estampa, llevaron a que desde muy pronto esta fuese señalada como de "lo más flojo de la serie, en los procedimientos del grabado y en la inspiración" ${ }^{50}$, concretándose, también que su dibujo "es falso, la composición carece de perspectiva y de verdad"51. Y, segundo $-y$ esto es todavía más importante- que hemos de dejar al margen las anécdotas para centrarnos en lo esencial: la reprobación de una justicia como la que la estampa evidencia; una justicia que -dictada por la ira y la sed de venganza- tiene unas leyes penales crueles y unas leyes distributivas discriminatorias - pues los mismos encargados de administrarla, mientras ahorcan a los hombres, violan (o consuelan) a sus mujeres-, y que, para colmo, son aplicadas por unos ministros tan faltos de entendimiento -como patentiza el físico grotesco del principal protagonista: el soldado del primer término-, que son capaces de distinguir el bien del mal, de modo que ellos mismos se convierten en genuinos malhechores. Consecuentemente, tampoco es extraño, que el atributo de la justicia en sus manos sea, en vez de una espada de doble filo y recta, un sable; pues, este, además de tener un único filo, se curva, como hacía la regla lesbia, para adaptarse mejor a lo subjetivo de los dictámenes de quien la utiliza, por lo cual él, fatalmente, terminará violando todo tipo de justicia ${ }^{52}$. Verdaderamente que esto sea así no es digno de admiración, sino de denuncia y reprobación.

Según Antonio Brum, la ignorancia que Goya glosó en las dos últimas estampas, "se remedia con sugetarse a la instrucción y buen consejo de los Directores", para, a continuación explicitar otros dos tipos de ignorancia que, según él, por el contrario, son "loables y de grande utilidad": la voluntaria y la magistral. La primera que es "la de aquellos que se contentan con saber lo que les basta para la pureza de su conciencia" es ilustrada sarcásticamente por Goya -que sin 


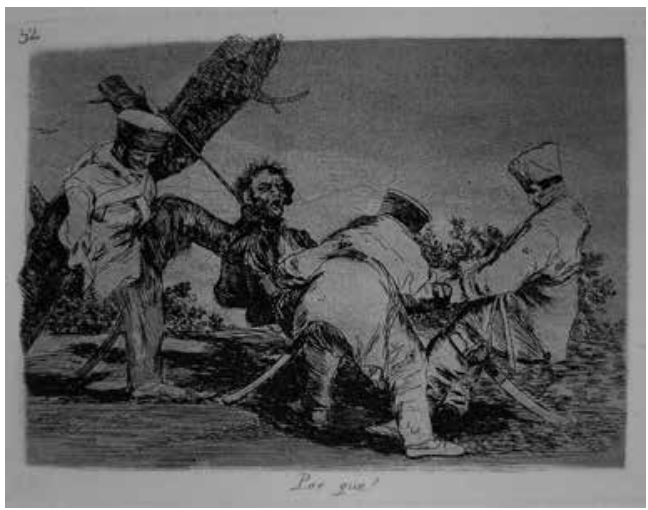

Fig.14. Goya. ¿Por qué

duda no cree que pueda haber una ignorancia que sea loable y de gran utilidad- en la siguiente estampa ¿Por qué? (Fig. 14) Sin duda, el autor de la letra y, por consiguiente, de la pregunta, es un ignorante voluntario que se contenta con saber -para mantener la pureza de su concienciael porqué de la tortura infringida al protagonista, en vez de escandalizarse por la aberración de la justicia que está supone, sea cual fuere la causa que la motivó. Quienes se mantienen en tal tipo de ignorancia voluntaria, podrán creer que mantienen pura su conciencia, pero, lo cierto es que nunca alcanzarán la virtud y la sabiduría.

Como tampoco las lograrán, los que poseen una ignorancia magistral, como el autor de la letra de la estampa siguiente que al preguntar ¿Qué hai que hacer más? (Fig. 15), glosaría -si lo interpretamos con socarronería-, el otro tipo de "ignorancia loable y de gran utilidad", rese-

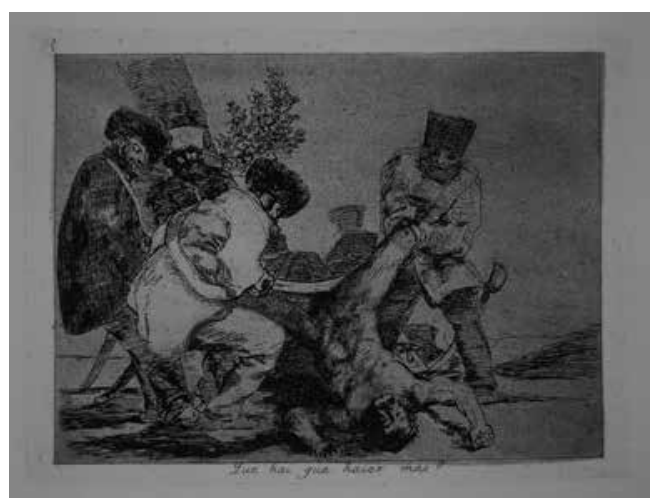

Fig.15. Goya. ¿Qué hai que hacer más? ñada por el autor del Proemio, a saber: "otra que ay Magistral, que perteneze a los muy doctos, a quienes el largo estudio, y desvelos, les dieron a conozer que es infinito más lo que el hombre ignora, qué quánto puede alcanzar a saber". Al autor de la pregunta, que sí es conocedor del tormento que hasta el momento le han infligido a la víctima, pero, siendo consciente de su propia ignorancia quiere aumentar su sabiduría no teniendo embarazo en preguntar para ilustrarse, qué otros suplicios todavía se le pueden infringir, tratando de llegar a conocerlos todos. Goya nos muestra sardónicamente que tales individuos podrán llegar a ser muy sabios en ciencias vanas, pero no por ello dejarán de ser unos necios, que jamás alcanzarán la virtud y la verdadera sabiduría. Tras la estampa está, por consiguiente, la doctrina de neoestoica contra la vanidad de la ciencia que no aporta nada a lo que realmente interesa al hombre, esto es: su constatación de que actúa conforme a la virtud. Si así lo hiciera, le tendrían sin cuidado las distintas clases de suplicio que pueden infringirse a un reo, $y$, por el contrario, se aprestaría a repudiar a los inhumanos.

El texto de Antonio Brum continua añadiendo una anotación a la ignorancia magistral: "De donde se infiere, que el más alto grado se sciencia feneze en principio desta sabia ignorancia, que confesó Socrates quando dixo. Unum scio, quod nihil scio". Desde luego, el autor de la letra de la siguiente estampa, al decir que el ajusticiado lo fue Por una nabaja (Fig. 16), es ejemplo de hasta qué punto fenece el más alto grado de ciencia ante la autentica ignorancia magistral que debería de reconocer, como Sócrates, que

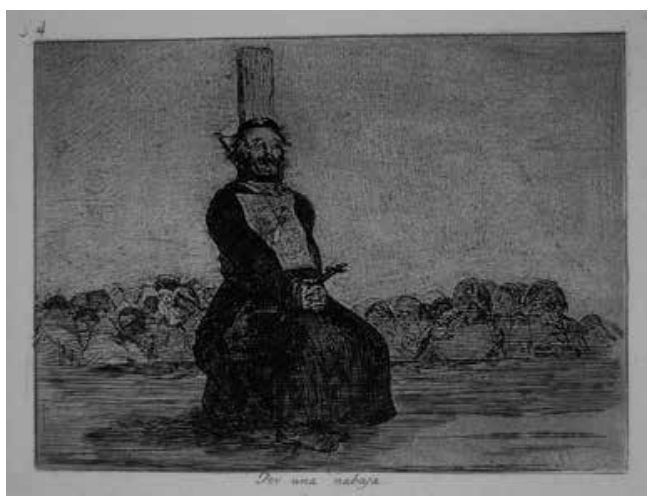

Fig.16. Goya. Por una nabaja 
solo sabe, que no sabe nada. Todo lo contrario, él cree, lleno de soberbia, que lo sabe todo y hasta es muy posible que esté orgulloso de ello, aunque objetivamente todo lo que conoce no solo es pura vanidad, sino que, incluso, no es toda la verdad $y$, de ella, precisamente, descifra la parte menos relevante, que es la que percibe más claramente por sus sentidos. Así él, que es un 'patriota', dice que el porqué de tan sumaria ejecución fue una 'nimiedad' como haber sido detenido el reo portando una navaja. Desde luego, esto es, en parte, cierto, y obviamente es fácil de apreciar, porque la lleva colgada al cuello, pero, sin duda, más importante es el hecho de que sea un guerrillero eclesiástico, como evidencia el gorro que lleva puesto, en el cual resalta una cruz que es la "señal distintiva y obligatoria de los miembros de las partidas de cruzada"53. Por eso para una persona desengañada, la verdadera causa del ajusticiamiento del reo -independientemente de cuáles fueran las leyes que le aplicaran los jueces, para darle tan cruel castigo- fue su modo vicioso de vida, totalmente contrario al orden sacramental que recibió, que lo llevó a emprender batallas por bienes mundanos e involucrar en ellas a su grey, en vez de dedicarse a su auténtico cometido que sería el de ser su guía espiritual, mostrándole el camino de la virtud y la verdad, que solo está atañido por la consecución únicamente de bienes espirituales. Así interpretada la estampa, podemos decir que no solo el autor de la letra-que desconoce lo mucho que no sabe-, sino también el principal protagonista de la estampa -que por no saber, ni tan siquiera sabe cuál es realmente su magis-

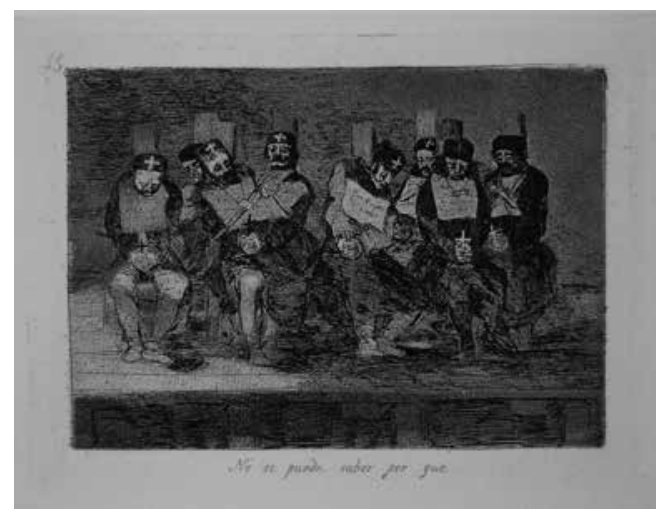

Fig.17. Goya. No se puede saber por qué terio- tienen una "ignorancia magistral", aunque, claro está, esta no sea la virtuosa socrática.

\section{Duda}

El texto de Antonio Brum, explicando la duda que genera comportamientos contrarios a la virtud:

La duda de que hablo aquí, no es aquella que usan los Prudentes en la variedad de sentencias y opiniones; hasta estar muy bien informados: (antes esta es muy útil, para aprovechar mucho en las sciencias) sino aquella que procede de flaqueza de entendimiento, que por incapaz de instrucción viene a parar en escrúpulos muy dañosos a la conciencia, y contrarios a la Virtud.

Pudiera llevarnos a pensar que el autor de la letra del grabado siguiente de la serie, No se puede saber por qué (Fig. 17), es un 'patriota', que se tiene por un hombre prudente, por lo que ante "la variedad de sentencias y opiniones", no puede, hasta estar mejor informado, dar razón de por qué fueron ejecutados los reos. Sin embargo, es obvio que en este caso, sí se puede saber por qué. Primero porque todos los reos tienen colgadas cartelas con sus sentencias escritas e, incluso, algunos las armas que tenían en el momento de ser detenidos $y$, segundo, porque la mayoría se cubre con el gorro con una cruz que los identifican inequívocamente como miembros de las partidas de cruzada. Lo que nos lleva a deducir que él, en realidad, es un hombre sectario, de corto entendimiento e incapaz de instrucción, por lo qué manifiesta escrúpulos a la hora de reconocer lo obvio: que los ajusticiados lo han sido precisamente por ser miembros de las partidas de cruzada y haber sido detenidos portando armas. Todo ello es muy dañoso a su conciencia ${ }^{54}$, ya que lo inhabilita para distinguir el bien y el mal obrar, tanto en lo que dictaminan las leyes humanas como las divinas. Las primeras -aunque pudieran considerarse injustas- decretan, en este momento, tal tipo de castigo y ejecución, para quienes cometan acciones como las que los reos han cometido. Las segundas, jamás justificarían que un clérigo, por el orden recibido, no solo renuncie a ser guía espiritual de su rebaño, sino que él mismo se convierta en un miembro de las partidas de cruzada, violando mandamientos como el de "no matarás". 
Brum señala que quien tiene tal flaqueza de entendimiento e incapacidad para la de instrucción viene a parar en escrúpulos que no solo son muy dañosos a la conciencia, sino que además son "contrarios a la Virtud". Comportamientos contrarios a la virtud que encontramos glosados en la estampa siguiente: Tampoco (Fig. 18). En ella están representadas dos maneras distintas de enfrentarse a la verdad ante la presencia de la muerte. Por una parte está la del autor de la letra, que, al igual que el de la estampa anterior, debido a la flaqueza de entendimiento y a la falta de instrucción, tiene dificultades para reconocer la verdad y distinguir la forma de obrar bien y mal, por lo que, falto también de voluntad, termina por desistir en conocer la causa de las ejecuciones y cree que obra bien, limitándose - por escrúpulos y para no decir mentira algunaa decir que "tampoco" se puede saber el por qué de ellas. Quizá si perseverase un poco más y se informara preguntando a entendidos, estos, teniendo en cuenta el tipo de ejecución aplicada a los reos, podrían decirle que como ellos eran "escaladores" -en este caso ladrones dados al saqueo en tiempos de guerra-, se les había aplicado el suplicio de escalera, como a los protagonistas de la estampa iDuro es el paso! (Fig. $19)^{55}$ y se les había colgado de un árbol como a los malhechores de la estampa La pendaison (Fig. 20) de Les Grandes Misères de la Guerre de Jacques Callot ${ }^{56}$.

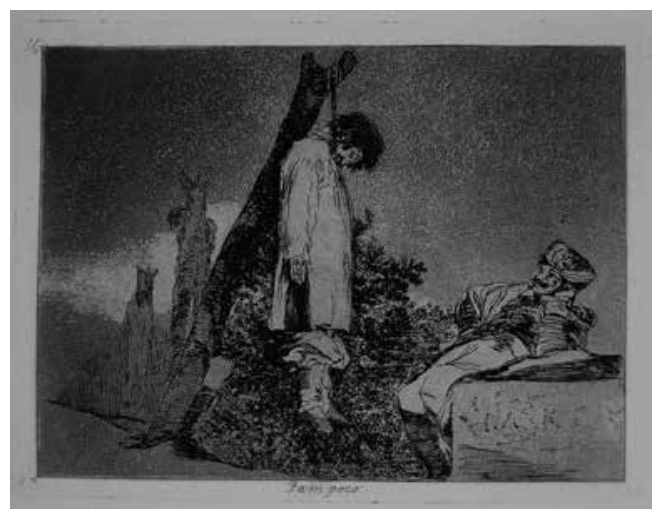

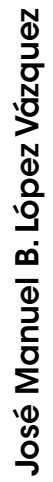

Fig.18. Goya. Tampoco

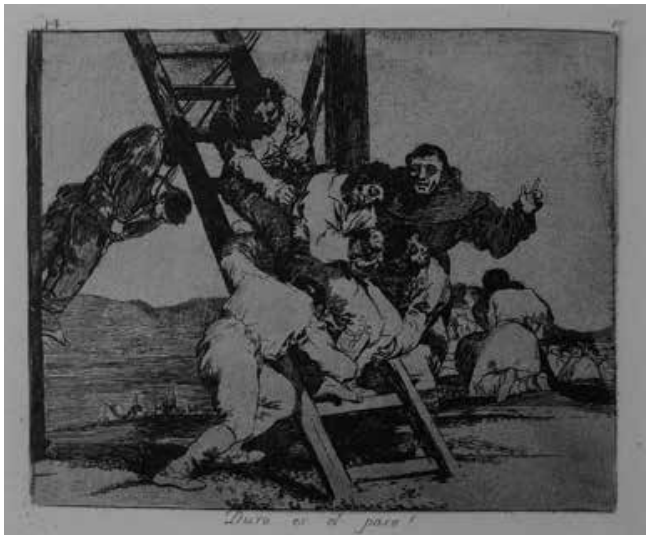

Fig.19. Goya. ¡Duro es el paso!

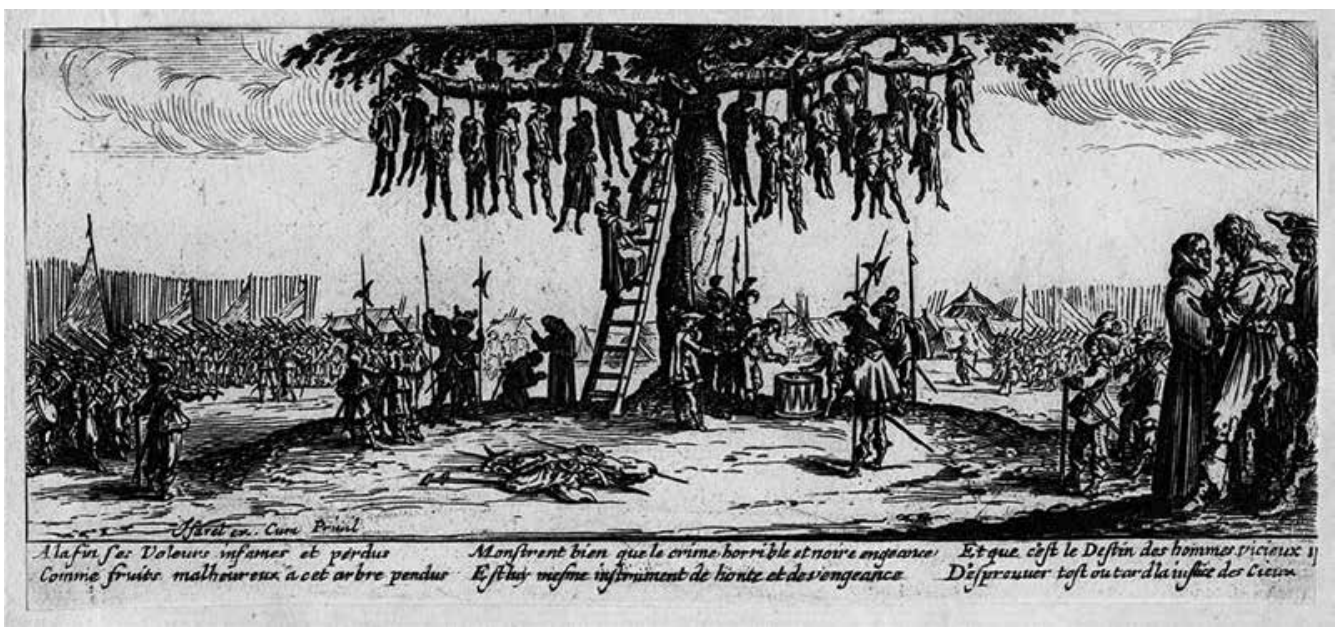

Fig.20. Jacques Callot. La pendaison 
El otro modo es el del soldado, el cual aparentemente tampoco tiene muchas luces -es tuerto de un ojo y medio ciego del otro- y al que parece que la acidia le entorpece todavía más el ingenio, produciéndole un letargo henchido de tristeza, que no le permite hacer nada bueno. Por consiguiente, es posible pensar que él ni tan siquiera se plantee preguntarse el por qué de las ejecuciones; ni que tampoco tenga escrúpulos de conciencia, sino que, simplemente, se considere un militar que cumple con su deber aplicando, aunque sea tediosamente, lo prescrito por la ley, sin pensar si ella es, o no, inhumana o contraria, o no, a la virtud. Lo cual, es hasta cierto punto es lógico, si tenemos en cuenta que él es un polaco -es decir: un paradigma de crueldad dentro del ejército francés- $y$, por lo tanto, un indolente; indolencia que estaría acrecentada por su ociosa pereza de ahí su postura: recostado y sosteniendo la cabeza con la mano izquierda, cuyo codo ${ }^{57}$ apoya en una piedra, tan infructuosa como él.

Sin embargo, también es posible que él no sea, a pesar de las apariencias, un hombre falto de entendimiento e incapaz de instrucción, sino simplemente un descarriado en el camino de la virtud. Y que como otros muchos desencaminados dados a la vida militar para satisfacer su vida viciosa, en un determinado momento de su $v^{\text {vida }}{ }^{58}$ la presencia de la muerte, se convierte en un memento mori, despertando en él un miedo a las postrimerías y el temor de Dios, y que, entonces, se muestre propicio para reemprender el camino de la virtud, reconvirtiendo la tristeza en la que los despeñó su vida viciosa, en fructuosa melancolía presta a dar frutos, una vez reintegrado a la vida civil. Para que pudiéramos darnos cuenta de sí en vez de ante un perezoso e indolente, estamos ante un melancólico, dubitativo de recuperar el camino de la virtud, tras preguntarse el porqué de la vida que lleva, sería necesario que lo viésemos nuevamente en acción. Al fin y al cabo, como dice la glosa de Gomberville al emblema La vertu presupose l'àction:

Le Peintre auroit bien voulu nous dire que cette lâche qui appréhende toutes choses, usurpe avec iniustice, le nom \& la resemblace de la vertu; mais sçachant que sa foiblesse \& la crainte ne doivent exerce sur elle qu'une courte tyrannie, il luy laisse les marques \& le nom de la vertu, \& les luy laisse avec beaucoup d'adresse. Car il la place de telle sorte quil n'y a qu'une très estroitte séparation entre elle la Fainéantise mesme, affin que par la comparaison de l' une \& le autre, les moins clairs voyans connoissent qu'elles ne sont presque point différentes. En effet nous n'y remarquons rien de dissemblable, sinon que la première qui n'est pas encore tout à fait léthargique, se soustient un peu sur le reste de sus forces; \& l'autre qui est ensevelie toute entière dans son ordure, \& dans son insensibilité, semble dire par son silence criminel, qu'elle se reioüit en son mal-heur; \& que c'est avec volupté, qu'elle renonce à cette vie toute glorieuse, \& toute divine que nos âmes reçoivent d'action ${ }^{59}$.

Aunque, a falta de ella, hay otras señales -como la piedra cúbica sobre la que se apoya ${ }^{60}$ y el hecho de que la ociosidad no lo haya aletargado por completo-, que nos dan indicios que él terminará por dejar la vida viciosa por la virtuosa. Precisamente, Antonio Brum concluye su descripción de los que pecan a causa de la duda escrupulosa diciendo: "Algunos sanan desta enfermedad por la destreza y prudencia de los Médicos espirituales, y otros mueren incurables".

Los tres grabados siguientes muestran que, por lo menos, el autor de la letra sí se ha curado y ha dado en la sabiduría. En la primera estampa, Esto es peor (Fig. 21) ha dejado de preguntarse la vanidad del porqué o del cómo de tan brutal empalamiento, para hacer un juicio de valor, juzgando el bien y el mal obrar, y apreciando que incluso en el mal, hay grados de perversión y que este modo de matar al reo es mucho más degenerado que los precedentes agarrotamien-

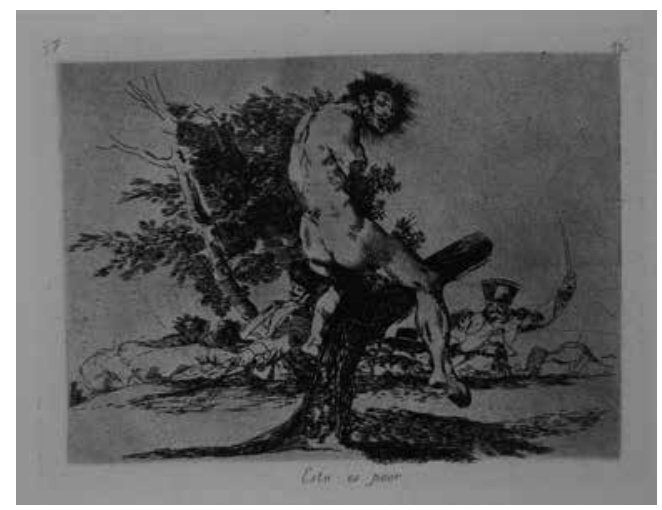

Fig.21. Goya. Esto es peor 


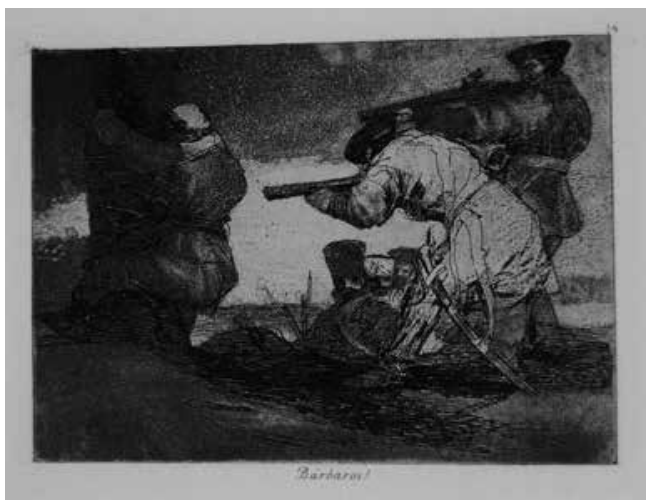

Fig.22. Goya. ¡Barbaros!

tos y ahorcamientos. En la siguiente, ;Barbaros! (Fig. 22), ya no solo realiza juicios de valor, sino que incluso se indigna para, finalmente, en la tercera, tomar una postura plenamente estoica y ecuánime al juzgar las atrocidades que es capaz de cometer el hombre -independiente de que sea su propia nacionalidad o de su bando contendiente- cuando actúa sin el freno de la justicia y de la razón, señalando sentenciosa y lacónicamente: Grande hazaña con muertos (Fig. 23).

Por lo tanto, en las tres últimas estampas hay una reflexión no solo sobre las aberraciones de la justicia, sino también sobre las de la jurisprudencia ${ }^{61}$. El ejército francés que presume de ser un defensor de la razón -y que de hecho las leyes francesas habían decretado la ejecución mediante fusilamiento en procura de un menor sufrimiento para el reo- está formado en realidad por bárbaros, es decir, "incultos, llenos de ignorancia y rudeza, toscos y salvajes" que, como tales, actúan de un modo "destemplado y precipitado e inconsideradamente violento" 62 atando al reo brutal e irracionalmente, encarándolo a un árbol, para ejecutar la sentencia. Es decir, todo lo contrario a lo que dicta la razón. Por su parte los

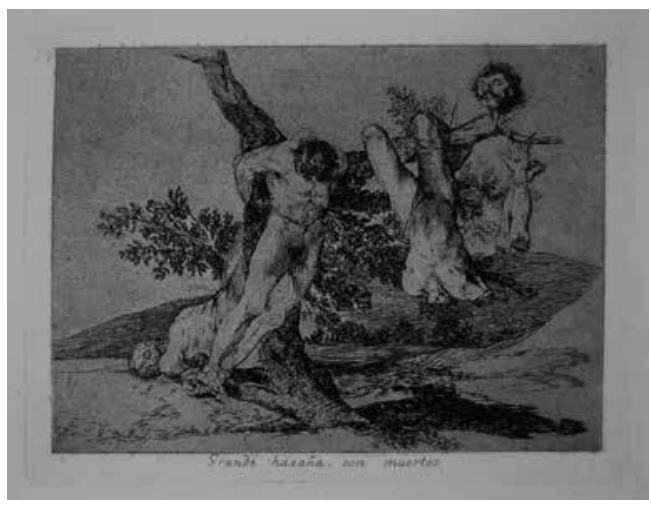

Fig.23. Goya. Grande hazaña con muertos

españoles que presumen de "piadosos" y que, por ello tenían señalado en las leyes del reino, para los extraordinarios y atroces delitos, el dar rápida muerte al reo y luego ensañarse con el cadáver ${ }^{63}$, actúan cuando tal hacen -como podemos ver en Grande hazaña con muertos-, en realidad, contra toda piedad. Claro está que estos últimos pueden ser todavía peores, cuando en vez de las leyes del reino, dictan "leyes municipales, y costumbres locales", como la de mutilar y empalar salvajemente al inculpado estando todavía vivo, aplicadas al protagonista de Esto es peor, que al parecer se inspira en un hecho concreto sucedido en Chinchón.

Goya, entonces, cierra la primera parte de Los Desastres mostrándonos como el autor, o, por lo menos, uno de los autores, de los epígrafes - ¿él mismo?- terminó dando en el desengaño. Ni más ni menos de cómo Antonio Brum remataba su Proemio al Theatro Moral: "En 65 años de edad, he visto y experimentado bastante los errores, desaciertos, y engaños del mundo, para tener dellos un perfecto desengaño; pues es muy loco, quien no escarmienta con los exemplos agenos". Y alienta al espectador a seguir el mismo camino. 


\section{NOTAS}

1 J.M.B. López Vázquez "Los Desastres de la Guerra de Goya como un libro de emblemas estoicos», en C. López, Ma A. Fernández y M $M^{a}$. I. Rodríguez (eds.), Barroco Iberoamericano. Identidades culturales de un Imperio, Vol. II, Santiago de Compostela, Andavira, 2013, pp. 275-304

2 M. Le Roy Gomberville, La doctrine des mœurs tirée de la philosophie des stoiques: représentée en cent tableaux. Et expliqué en cent discours pour l'instruction de la ieunesse. Imprimerie de Louys Seuestre, Paris, 1646, Prefacio, s.p.

${ }^{3}$ Theatro Moral de la Vida Humana en cien Emblemas; con el Enchiridion de Epitecto, \& y la Tabla de Cebes, Philoso Platónico, Francisco Foppens, Impressor y Mercader de Libros, Brusselas, 1672.

${ }^{4}$ M. Le Roy Gomberville, La doctrine des mœurs...

${ }^{5}$ B. Rosa de Gea, "La vida es buena: estoicismo y pensamiento barroco" [consulta: 03/03/2013] http://saavedra Fajardo.um.es/web/archivos/NOTAS/ RE0050.pdf, pp. 4-5.

6 "Pero lo más destacable en la doctrina del juicio y de los afectos quevediana es el acento puesto en la noción de «desengaño»-noción que, como ya apuntamos al hablar del Brocense, tiene su origen en la propia lógica estoica del juicio, en la medida en que el desengaño consiste, en La cuna y la sepultura, en un juicio por el que consideramos errónea toda la atribución de valor que previamente le habíamos concedido a algo. La moral de Quevedo es, como toda moral estoica, una moral de la virtud y la vida interior, pero se trata ante todo de una doctrina del desengaño y una doctrina desengañada. Nos enseña que todas nuestras tribulaciones nacen de nuestra falsa apreciación de las cosas. Pero si algo le interesa a Quevedo no es otra cosa que señalar cuán falsa es nuestra apreciación y disuadirnos enérgicamente de ella" (D. Domínguez Manzano: "El estoicismo como moral en Vives, el Brocense y Quevedo", Ingenium. Revista de historia del pensamiento moderno, $\mathrm{n}^{\circ}$ 5, 2011, pp. 128-129).
7 Ídem, p. 106.

${ }^{8}$ Véase, por ejemplo, A. Palomino de Castro y Velasco, Tomo segundo. Práctica de la Pintura, en que se trata de el modo de pintar a el olio temple, y fresco, con la resolución de todas las dudas, que en su manipulación pueden ocurrir. Y de la Perspectiva común, la de Techos, Ángulos, Teatros, y Monumentos de Perspectiva, y otras cosas muy especiales, con la dirección, documentos para las ideas, o Assumtos de las Obras, de que se ponen algunos exemplares, Viuda de Juan García Infançon, Madrid, 1724, p. 146.

9 Obra de la que Goya también tomó su formato. Debemos darnos cuenta que Los Desastres son una serie de estampas, que, como la precedente de los Caprichos conforman, en realidad, un libro. En el caso los Caprichos, él había mantenido la estructura triple de los libros de emblemas con una figura, un lema y un comentario, que habría sido añadido posteriormente, como también había sido el caso de la Emblemata Horaciana. En Los Desastres, al no haber sido publicados en vida del pintor, solo nos han llegado las figuras y los lemas y no sabemos si llegaron a existir los comentarios.

${ }^{10}$ Theatro Moral..., Proemio, s. p.

11 "El rey don Alonso primero de Aragón y Nápoles dezía: que la victoria era acción de la fortuna; la clemencia lo era del vencedor; pues desta se conseguía más aplauso que de aquella y era mayor gloria, conceder la paz, a quien pedía que hacer la guerra al que la rehusaba, y que él había ganado más fuerzas con la opinión de su piedad, que de sus armas, como se había conocido en cerco de Gaeta" (A. Mendo, Príncipe Perfecto y ministros ajustados documentos políticos y morales, Diego de Cosío, Salamanca, 1657, p. 206)

12 "Constancio escribe Sigonio que habiendo vencido con grande estrago a Magencio tirano, junto al Mesa de Panonia, o Hungría, con muerte de treinta mil hombres quando por la mañana subió en una colina y vio la campaña y rio lleno de cuerpos muertos, Iloró, no tanto de alegría por la vitoria, quanto movido de dolor por los difuntos: y mando sepultarles a todos sin distinción y curar los heridos que halló vivos" (J. Solorzano Pereira, Emblemas Regio-Políticos, Bernardo Noguês, Valencia,1658, Década décima, p. 113)

13 "La razón porque los más agudos y penetrantes ingenios, no son los más propios para esta professión [sabio o virtuoso] (como apunte arriba) es, porque presumiendo de sí, más de lo que son; gastan la mayor parte de su vida en la curiosidad de querer saber y examinar; lo que solamente aperciben por los sentidos, sin hazer jamás una sola reflexión sobre los mismos, que es el verdadero principio de este estudio, sin el qual todas las demás sciencias son inútiles" (Theatro Moral..., Proemio, s.p.)

${ }^{14}$ En ambos casos, los franceses actúan airados procurando saciar su sed de venganza, lo cual les lleva a un modo de comportarse viciado en el que las armas van sin dueño que las rijan, como ya denunciaba Quevedo: "Si dos cosas apartases de tu ánimo (tanto por dañosas, como inútiles) serás buen ignorante. La primera es no entristecerte en las desdichas: y la segunda, no airarte, ni encolerizarte en las ocasiones [...]. Veamos aora, ¿parécete bien según esto ir a la vengança y al castigo ciego y sin razón, ni entendimiento ninguno, ageno de ti mismo, quando más te avías menester? Ten por cierto, que bien puedes tu ir con ira cargado de armas; mas que las armas van sin ti, y sin dueño, que las rija. $Y$ yendo airado, tendrás más razón de temerte tú a ti mismo, que el contrario de temerte a ti, viendo que vas enojado. $Y$ es sin duda, que peligras en ti más y peor" (F. de Quevedo, La cuna y la sepultura, Imprenta del Reyno, Madrid, 1634, pp. $47 v-50 r$ ).

15 "Aparece [la Misericordia] con los brazos abiertos para representar adecuadamente que la Misericordia, a imitación de Cristo, Señor y Redentor Nuestro, en quien radica la Misericordia verdadera, siempre nos estará esperando con prontitud con los brazos abiertos, para subvenir nuestras miserias y abrazarnos a todos; sobre lo cual dice Dante, en el lib.III del Purgatorio: Horribles fueron mis pecados,/ mas la infinita bondad tan amplios brazos tiene/ que toma cuanto a ella se encomienda" (C. Ripa, Iconología, Madrid, Akal, 1987, T.Il, p.89). 
16 "La clemencia es una virtud del ánimo que mueve el hombre a la compasión, haciéndolo más fácil en el perdonar y pronto en el socorrer. Se pinta sentada, simbolizando con ello su quietud y mansedumbre" (Ídem, p.192).

17 "Lo primero que observé fue esta disposición de todo el cuerpo, tan derecha, sin que tuerça, a un lado ni a otro.

- Fue el hombre -dixo Artemiacriado para el cielo, y assí crece hazia allá; y en essa material rectitud del cuerpo está simbolizada la del ánimo, con tal correspondencia, que al que le faltó por desgracia la primera sucede con mayor faltarle la segunda.

- Es assí dixo -Critilo- donde quiera que hallamos corvada la disposición, rezelamos también torcida la intención; en descubriendo ensenadas en el cuerpo, tememos haya doblezes en el ánimo; el otro a quien se le anubló alguno de los ojos, también suele cegarse de passión, y lo que es digno de más reparo que nos les tenemos lástima como a los ciegos, sino rezelo que no miran derecho; los coxos suelen tropeçar en el camino de la virtud, y aun echarse a rodar, coxeando la voluntad en los afectos; faltan los mancos en la perfección de las obras, en hazer bien a los demás. Pero la razón, en los varones sabios, corrige todos estos pronósticos siniestros" (B. Gracián, El Criticón, Santos Alonso (ed.), Cátedra, Madrid, 1984, pp. 189-190). El refranero también, dice: "No fíes en los hombres tuertos, ni menos corcovados; si los cojos fuesen buenos, escríbelo por milagro".

18 "Les nez ronds et estoupez: de betize et de fureur» (J. Lagniet, Recueil des plus illustres proverbes, Divises en trois Livres, Le Premier contient les proverbes moraux. Le Second Les proverbes joyeux et plaisans. Le Troisiesme Represente la vie des Gueux en proverbes mis en la lumiere par lacques Lagniet a Paris sur le quay de la Megisserie au fort I'Evesque, 1657, Libro II, p.61).

${ }^{19} \mathrm{~A}$. Palomino de Castro y Velasco, Tomo segundo. Práctica de la Pintura, en que se trata de el modo de pintar a el olio temple, y fresco, con la resolución de todas las dudas, que en su manipulación pueden ocurrir. Y de la Perspectiva común, la de Techos, Ángulos,
Teatros, y Monumentos de Perspectiva, y otras cosas muy especiales, con la dirección, documentos para las ideas, o Assumtos de las Obras, de que se ponen algunos exemplares, Viuda de Juan García Infançon, Madrid,1724, p. 112).

20 "Son [las narices] como el gñomón del relox del alma, que señalan el temple de la condición: las leoninas denotan el valor, las aguileñas la generosidad, las prolongadas la mansedumbre, la sutiles la sabiduría y las gruesas la necedad" (B. Gracián, El Criticón..., p. 198).

21 J. Lagniet, Recueil des plus illustres proverbes... Libro II, p.61.

22 "Pero Isaias los dibuxa mejor (a los fingidos) cuando les dize, ¿porqué pesays plata, y contays dinero, y no comprays pan, y consumís vuestro trabajo y no en hartura? lo qual dize por estas gentes, pues con los trabajos que emprenden, pudieran comprar el pan de la gloria, y la hartura del Cielo, y no quieren sino emplear su caudal en tan viles mercancías. Todo aquesto hazen los fingidos, y la prueva de su intencion, es que luego que se les ofrece el interés acuden, según lo que cuenta Niseno de cierto embaucador, y una Mona con que andava ganando, y es que andando metida en su juego, le arrojaron algunas almendras, y dexando el juego arremetió con ellas, y dize que ansi hazen los hypócritas fingidos, que no les dura más su invención de quanto no se les ofrece el interés. Bien semejantes a lo que haze el cernícalo lagartijero, que parece que anda floreando en el aire por gozar de las mareas del cielo, y está mirando las viles sabandijas en que ha de hazer presa. Por esto puso entre sus preceptos Pitágoras que no se crie en la ciudad aves de corvas uñas, significando los que disimuladamente roban y por tanto dize Isichio que se prohibían en la ley, porque son symbolo de los que parece que están contemplando en cosas altas y sublimes, y andan a caça de sus intereses"(F. de Villava, Empresas Espirituales y Morales, en que se finge, que diferentes supuestos las traen al modo estrangero, representando el pensamiento, en que más pueden señalarse: assí en virtud, como en vicio, de manera que pueden servir à la Christiana piedad, Baeza, 1613, p. 74).
23 "El hombre inverecundo, o sin vergüenza, ha de tener el rostro redondo; la nariz aguileña, los ojos muy abiertos, y refulgentes [...] la postura encorvada" (A. Palomino de Castro y Velasco, Tomo segundo. Práctica de la Pintura..., p. 112).

${ }^{24}$ Posiblemente esta mujer, aparentemente rebosante de clemencia, vive de mostrar sus monstruos como hace la protagonista del dibujo de Goya del Álbum E. Cosa rara.

${ }^{25} \mathrm{~J}$. Lagniet, Recueil des plus illustres proverbes... Libro II, p.61.

26 "La tercera fuente de nuestros apetitos es una complexión cálida y sanguínea, que enciende en el coraçon varios deseos, semejantes a un fuego de paja, que a los principios son violentos, más no tienen duración" ( $\mathrm{N}$. Caussin, La Corte Santa, Rafael Figueró, Barcelona,1718 p. 398).

${ }^{27}$ A. de Villegas, Flos Santorum y Historia General en que se escribe la vida de la Virgen Sacratísima madre de Dios, Señora Nuestra y Las de los Santos Antiguos que fueron antes de la venida de nuestro Salvador, Narciso Oliva, Barcelona,1794, p. 584.

${ }^{28}$ D. Saavedra Fajardo, Empresas Politicas, Sagrario López (ed.), Cátedra, Madrid, 1999, p. 1016.

${ }^{29}$ Tales despropósitos legales, así como su, no menos desatinada aplicación, ya fue puesto pormenorizadamente por Jesusa Vega (J. Vega, Fatales consecuencias de la guerra, Francisco de Goya Pintor, en Francisco de Goya. Grabador. Instantáneas. Desastres de la Guerra, Caser, Madrid,1992, pp. 33-39).

${ }^{30} \mathrm{~J}$. de Solorzano Pereira, Década nona..., p. 117.

${ }^{31}$ Como dice el epigrama del emblema "Las guerras entre reyes desquician a los pueblos" de Solórzano: Si Noto y Boreas se enojan/ amenaça gran tormenta/ este sopla, aquel alienta/ guerra en las aguas crecen./ ¿El Piélago qué ha de hazer/ si el uracán le conturba?/ precipitado se turba,I todo es rabiar, y temer./ El pueblo es el mar, el Rey viento,/ si guerra cruel se levanta,/ la plebe gime, y se espanta/y se atreve a los sangriento" (Solorzano Pereira, década nona..., pp. 412-413). 
32 "Y lo que es peor y más digno de llorar, que estas calamidades no nacen solo de la venida y excesos del enemigo, sino de nuestros propios soldados, cuya insolencia y desenfrenado descoco y rapacidad, no ay cosa que no sujete desde luego que asientan plaça en las banderas. Ora marchen, o se aloxen en los lugares de los labradores, o se pongan en los quarteles [...] refiriendo muchos destos daños, y venganças que por esta causa suelen tomar de los vezinos, deseando se renovase la severidad de Aureliano, Tamor y otros Capitanes, para enfrenar esta licencia y lo relaxado o vicioso de la milicia" (Ídem, pp. 433-34).

${ }^{33}$ Creyendo que esta mísera ruina/ no es suya, sino más de su consorte,/ y los hijos amados, desatina, /y sin que nada su furor reporte,/ las armas arrebata azelerado/ aunque jamás las aya manejado. IAl que encuentra ora sea conocido,/ o no, ora amigo o enemigo sea,/ Igualmente le enviste enfurecido,/ le desnuda, y despoja sin pelea,/ con rústico furor, pues inhumano/ no puede ser más, que el que villano (Ídem, pp. 437-438).

${ }^{34} \mathrm{Al}$ ser considerado como uno de los suyos, y teniendo en cuenta la postura patriótica del autor de la letra, es probable que el ajusticiado no sea un afrancesado, como recoge repetidamente la bibliografía a partir de Mélida.

${ }^{35}$ En este caso, sí es probable que la victima fuera un afrancesado o un soldado francés.

36 "Puis quiil est constant que la vertu est également ennemie des extrêmes, concevons de bonne heure cette importante vérité, que le crime est toujours crime: \& bien que le temps, le lieu, ou quelqu'autre circonstance y mettent de la différence, il est vray néanmoins qu'ils n'en changent point la Nature» (M. Le Roy Gomberville, La doctrine des mœurs..., p 9v-10r).

37 Esta interpretación de bondad o maldad basada en la disparidad de posturas, la encontramos por ejemplo en Solorzano Pereira cuando dice: "esto mismo dejando otros muchos exemplos, dize Iulio Ferreto que sucedió en la memorable batalla de Ravena, en tiempo de lulio II, Pontife Romano, año 1512, contado después de otro, que fue testigo de vista, y que murieron de entrambas partes más de treinta mil hombres, de suerte, que aunque los Franceses blasonavan de quedar vencedores, todavía están Ilorando el grave estrago que padecieron. $Y$ añade lo que es más de admirar, que los cadáveres de los Españoles y sus amigos, que pelearon por parte de la Iglesia, quedaron boca arriba con los ojos abiertos, como mirando al cielo, y los de los Franceses, y facción contraria, boca abajo con miserable espectáculo, denotando las penas eternas, que ya padecían" ( J. de Solórzano Pereira, década nona..., pp. 439-440).

${ }^{38} \mathrm{R}$. Wolf, "Withness and Judge in Goya's Disaster of War", en Fatal Consequences: Callot, Goya and the Horrors of War, Hood Museum of Art, Dartmouth College, Hannover, 1990, p. 43.

${ }^{39}$ C. F. Menestrier, L'art des emblèmes: ou, s'enseigne la morale par les figures de la fable, de l'histoire, \& de la nature. Ouvrage rempli de prés de cinq cent figures, Chez R.J.B. de la Caille, 1684, Paris, p. 49.

40 "Moza de Fortuna. Se toma regularmente por la muger expuesta o mundana" (Diccionario de Autoridades)

${ }^{41} \mathrm{~J}$. Le Goff y N. Truong, Una historia del cuerpo en la Edad Media, Ed. Paidós, Barcelona, 2005, pp. 12-13.

${ }^{42}$ El mismo acopio de objetos dispuestos sin orden ni concierto, en el espacio e, incluso, quebrados o torcidos, lo encontramos en la ilustración de Jacques Lagniet del proverbio "Nul ne se connoit soy mesme" (fig. 12), aunque en este caso, la escena se completa con una persona mirándose al espejo (J. Lagniet, Recueil des plus illustres proverbes..., Libro I, p. 44)

${ }^{43}$ De hecho, el recuadro con la ilustración de Jacques Lagniet -que he citado anteriormente del proverbio "Nul ne se connoit soy mesme"- se inserta en una escena en la que varios protagonistas buscan revolviendo objetos caóticamente amontonados, utilizando lámparas encendidas, aparentemente imitando a Diógenes de Sinope, aunque ellos son sus contrafiguras, pues procuran cosas -bienes terrenales- y no personas y, también, al hacerlo utilizando anteojos, los cuales solo les permiten ver los antojos generados por sus pasiones. El epígrafe del pie del grabado dice: "Tout le monde cherche sa commodité, tout le cherche a faire ses afaires, tout le monde porte envie de tous costez, et de toutes pars au profit particulière, celuy cy tire, I'autre attire, et tous ont un mesme amour d'avoir» (Ibídem)

${ }^{44}$ Además de refranes como el recogido por Correas "La admiración es hija de la ignorancia", debemos tener en cuenta que el no admirarse es propio del estoico, así Quevedo dice: "Acaba de persuadirte a que dentro de ti mismo tienes que hacer tanto que, aun por larga que sea tu vida, te faltará tiempo; y que no puedes saber nada bueno para ti, si no fuere lo que aprendieres del desengaño y de la verdad; y que entonces empezarás a ser sabio, cuando no temieres las miserias, ni codiciares las honras, ni te admirares de nada y tú mismo estudiares en ti, que leyéndote está tu naturaleza introducciones de la verdad. Cada día, y cada hora que pasa es un argumento que precede para tu desengaño a la conclusión de la muerte" (F. de Quevedo, La cuna y la sepultura, Madrid, Imprenta del Reyno, 1634, pp. 59 va $^{\mathrm{a}}-60 \mathrm{r}^{\mathrm{a}}$ ). Goya ya había utilizado la admiración con el mismo sentido de ignorancia en otras estampas de la serie como ¡Qué valor! y ¡Duro es el paso! o en Caprichos como ¡Que se la llevaron! (véase José Manuel B. López Vázquez "Sabiduría y experiencia. Los Caprichos 6, 7 y 8: engaño del mundo y rapto de la verdad, Quintana, 2002, p. 69) o ¡Linda maestra! (José Manuel B. López Vázquez, "Goya, Sueños y Caprichos" en José Manuel B. López Vázquez y Juan M. Monterroso Montero, Goya y Dalí, Fundación Artes, Santiago de Compostela, 2004, p. 66).

${ }^{45}$ E. Lafuente Ferrari, Francisco de Goya. Los Desastres de la Guerra, Gustavo Gili, S.A., Barcelona, 1979,p. 53.

$46 \mathrm{~J}$. Vega, Fatales consecuencias de la guerra..., p. 36.

${ }^{47}$ E. Lafuente Ferrari, Francisco de Goya. Los Desastres..., p. 53.

$48 \mathrm{~J}$. Vega, Fatales consecuencias de la guerra..., p. 36.

49 Ya el Conde de la Viñaza señalaba como Goya había ido empeo- 
rando técnicamente la obra a medida que avanzaba en su proceso "Cuanto más corregía Goya este cobre, ya con nuevas mordeduras, o con aguadas de agua fuerte, ya con el agua tinta o usando la punta seca con esplendidez, otras tantas veces la dejaba más desairada e incorrecta" (Conde de la Viñaza, Goya, su tiempo, su vida, sus obras, Tipografía de Manuel G. Hernández, Madrid, 1887, pp. 378-379).

${ }^{50}$ lbídem.

51 Ibídem. Lo que fue constantemente repetido por los autores posteriores, así Beruete todavía concreta más:"Es una composición fea y de mal gusto, que no produce el efecto deseado de terror; resulta caricaturesca" (A. de Beruete, Goya grabador, Blass, Madrid, 1918, p. 81) y Lafuente Ferrari, específica: “En mi opinión, es uno de los peores grabados de la serie, como algunos otros que tienen estas figuras grandes, con dibujo es flojo y desflecado. Por otra parte, el grupo de la izquierda está confuso y mal resuelto" (E. Lafuente Ferrari, Francisco de Goya. Los Desastres..., p. 53)

52 "Los penales significan por la espada, símbolo de la justicia, como lo dio a entender Trajano cuando dándosela desnuda al prefecto Pretorio, le dijo: « Toma esta espada y usa della en mi favor si gobernare justamente; $y$, si no, contra mí.» Los dos cortes della son iguales al rico y al pobre. No con lomos para ofender al uno y con filos para herir al otro. Las leyes distributivas se significan por la regla o la escuadra, que mide a todos indiferentemente sus acciones y derechos. A esta regla de justicia se han de ajustar las cosas; no ella a las cosas, como lo hacía la regla Lesbia, que por ser de plomo se doblaba y acomodaba a las sombras de las piedras" (D. Saavedra Fajardo, Op. cit., 358)

${ }^{53} \mathrm{G}$. Dufour, Dufour, Goya durante la guerra de la Independencia, Cátedra, Madrid, 2008, p. 133.

54 "Conciencia. Ciencia de sí mismo, o ciencia ciertísima de aquello que está en nuestro ánimo, bueno o malo" (Diccionario de Autoridades).

55 J.M.B. López Vázquez, "Los Desastres de la Guerra de Goya como un libro..., pp. 298-299.

${ }^{56}$ Cuyo epígrafe es: «A la fin ces voleurs infâmes et perdus, / Comme fruits malheureux a cet arbre pendus./ Montrent bien que le crime (horrible et noire engeance)/ est luy mesme instrument de honte et de vengean$\mathrm{ce}, /$ Et que c'est des hommes vicieux,/ Désprouuer tost ou tard la justice des Cieux».

${ }^{57}$ Lo que denotaría su modo de vivir carnal, pues como señala Ripa: "Queriendo pintar a un hombre deleitoso y entregado a los placeres, lo representaremos tal como lo describe Pieiro Valeriano en su lib. XXXVI, muy cómodamente sentado y apoyándose en un cojín con el codo. Refiere sobre esto Adamantio que era signo de voluptuosidad y lascivia el apoyar el codo en un cojín" (C. Ripa, Iconología..., T.I., 268). Goya sustituye el cojín por un cabo de la propia capa del militar.

${ }^{58}$ Como le pasó a Antonio Brum, según el mismo relata en su autobio- grafía, aunque en su caso la razón no fue la presencia de la muerte, sino la de contraer matrimonio.

${ }^{59}$ M. Le Roy Gomberville, La doctrine des mœurs... p. 7.

${ }^{60}$ Recordemos que esta es un atributo de la meditación melancólica, que ya aparece en el grabado del Poeta de José Ribera, y que ya Ripa, señalaba que "La roca en la que se apoya muestra como el melancólico es muy duro y estéril de obras y palabras, tanto para sí mismo, como para los otros, al igual que la roca que no produce hierba, ni permite tampoco producirla en la tierra que tiene por debajo. Mas si bien nos parece estar ociosos en lo que el invierno de sus acciones políticas, llegando la primavera, cuando se advierte la necesidad de hombres prudentes, resultan ser a veces los melancólicos los mejores y más experimentados, acertados de juicio y juiciosos de mente" (Ibídem, V.II, p. 65).

${ }^{61}$ Antonio Brum ya subrayaba en su Proemio al Theatro Moral sus dudas sobre que los faltos de entendimiento pudieran aplicar la justicia, cuanto más teniendo en cuenta lo enrevesado de la jurisprudencia.

62 Diccionario de Autoridades.

63 "Para extraordinarios y enormes delitos, ay señalados atroces castigos en las leyes de nuestro Reyno; pero la piedad las ha interpretado, y dando muerte veloz al delincuente, se executa en su cadáver, lo que mandan. Basta esa demonstración para el horror y el escarmiento" (A. Mendo, Príncipe perfecto ..., p. 146). 